\title{
You have to be joking: Are communities loosing respect for health and safety policy, programs and systems?
}

\author{
Nicholas Oughton \\ Griffith University, Queensland, Australia
}

Correspondence: Nicholas Oughton. Address: Queensland College of Art, Griffith University, PO Box 3370 , South Brisbane, Queensland, 4101. Australia. E-mail: n.oughton@griffith.edu.au

Received: May 13, 2013

Accepted: November 12, 2013

DOI : $10.5430 /$ jha.v3n5p115

URL: http://dx.doi.org/10.5430/jha.v3n5p115

\begin{abstract}
OHS management systems and professionals have done much to ensure the health and safety of workers and societies in general. However, where these systems have become complex, overbearing and authoritarian, they have stifled workers and the community's ability to respond to unique or unanticipated occurrences of occupational and general risk.

This predicament is exacerbated when the general public lose faith in an OHS culture that has "gone mad", or become "out of control", and where "open season" has been declared by the media on safety regulators, their systems and regulations. This may be a perceived rather than actual truth, however, perceptions drive personal attitudes and responses, and the reputation and effectiveness of OHS is at stake.

Driving some contemporary attitudes towards OHS is a barrage of lampoon, satire and angry comment pervade by mischief-makers, the press and the electronic media. The profession has also looked into the mirror and revealed areas of self-doubt. This paper looks at an unfolding and worrying scenario for occupational health.
\end{abstract}

\section{Key words}

Occupational health, Risk management, Safety management, OHS futures

\section{I ntroduction}

Mention at a dinner party, a barbecue or at the pub that you work in or are involved with OHS, and you will be rewarded with polite silence, sympathetic smiles or abuse. You may be informed that OHS is "out of control" and constraining community activities through overregulation, or told that the restrictions and costs of applying OHS in small business is an increasing and a chronic burden ${ }^{[1]}$. In some respects, the very legitimacy of OHS Regulatory authority is being called into question.

In a paper prepared for Safe Work Australia, Valerie Braithwaite reported, “The arbitrary use of power is central to the idea of rule of law... When a regulatory agency uses its power to target entities or individuals without acceptable justification, public concern turns from soundness of purpose to justice and due process". Braithwaite continues, "Doubts about benefits and justice undermine cooperation at a number of levels. Most seriously, such doubts raise concerns over 
the legitimacy of the authority”. Braithwaite suggests that the contempt, that may arise from a loss of legitimacy is: “A posture displayed toward regulatory authorities that have lost the respect of the public...The objective becomes one of finding pathways around the law - finding the weaknesses, exploiting loopholes, and rejecting the principles that underpin law and give it meaning” ${ }^{[2]}$.

Antagonism towards OHS flourishes despite the fact that safety regulations, standards, principles and practices have successfully and dramatically reduced workplace injuries, rates of disease and the chance of death for most working men and women. From the Factory Acts of the nineteenth century, the surge of workplace health and safety legislation that occurred in the 1960s and 1970s, to a contemporary OHS reformation in Australia ${ }^{[3]}$, working conditions have dramatically improved for most workers. Much credit for this achievement should be given to unions, professional safety organizations, many (but not all) employers, government legislators, OHS educators and, most importantly, workers at the forefront of production and service delivery.

Fuelling community hostility towards OHS is a plethora of pejorative comment, lampoon and derision occurring in the media. Stories of OHS "gone mad" are a regular feature of tabloid newspapers - particularly in the United Kingdom, where "open season" has been declared on safety regulators and enforcers. In 2009, British Prime Minister David Cameron (then leader of the opposition) joined the fray, calling for a review of the: "Excessive, over the top health and safety culture that is causing problems in our country today" ${ }^{[4]}$. A year earlier, in 2008, a more balanced and less combative approach was signaled when Australian Prime Minister Julia Gillard (then Minister for Education) launched the government's OHS Harmonization policy. This recognized the challenges faced by the business community, stating that: "Harmonizing OHS laws ... will cut red tape, boost business efficiency and provide greater certainty and protections for all workplace parties” ${ }^{[5]}$.

It is not just business and the community who question the appropriateness of contemporary OHS and its management. The safety industry is questioning its own agenda, in particular its role in twenty-first-century working life and communities, and how occupational safety management might be improved.

\section{A personal perspective}

The author became involved with OHS when appointed Workplace Health and Safety Officer (WHSO) at his place of employment, and soon developed an interest for what had become a new discipline - one that, according to eminent OHS specialist Michael Quinlan, was becoming an issue of "major significance for governments, employers, unions, professionals, workers and the community in general” ${ }^{[6]}$.

The new Workplace Health and Safety Act 1989 had recently been introduced in Queensland, Australia and WHSO courses provided an introduction to the rudiments of OHS and a grounding in the new legislation and its supporting regulations. A statement set out in bold type in the course notes is clearly remembered: "No job is so important and no service so urgent that we cannot take time to perform the work safely" ${ }^{[7]}$. In these seemingly pioneering days, the impression was that great strides were being made towards making life safer for workers and their communities.

Speaking of more recent times, David Tregoweth, OHS Manager at Brambles, commented that: "There has been little progress in real terms to safety management, risk reduction and injury prevention". He suggests that this is due to an influx of Safety Managers with "great knowledge ... around legislation and the rules of safety" ${ }^{8]}$, but little local knowledge or front line experience. Further, he suggests that although lost time injury frequency rates, severity and duration appear to be declining, this is due mostly to "creative accounting" by those who have an investment in showing continuous improvement in OHS performance.

Tregoweth believes that those most suited to achieving advances in risk-reduction and safety management are those at the point of production or service - people who "really know how things work and what the real business and organizational 
issues are", those with a "real insight into why successive programs for quality, safety and cultural change delivered or failed to deliver". Risk manager Adrian Savage calls this zone "the point of risk" ${ }^{[9]}$. Savage argues that those most likely to effectively manage a hazard are those who most intimately feel its impact. Tregoweth is particularly scathing of some forms of safety management, which he believes "just get in the way - too many rules, too many audits, too much red tape and too few results” ${ }^{[10]}$.

\section{Purpose}

The loss of legitimacy, and the contempt displayed towards OHS by some sections of the public compromises the authority, credibility and effectiveness of its mission This article looks at the often satirical, sometimes hysterical, but occasionally valid critique of contemporary OHS that has occurred in the electronic and print media. Second, it discusses some concerns about the current OHS paradigm raised by safety professionals. Third, it attempts to draw these two threads together and reach conclusions regarding future directions.

\section{Is OHS becoming a joke}

Health and safety officials and other safety types have become targets of ridicule, mockery and gentle derision in some television programs. The drama series Kingdom, starring Stephen Fry is a good example. A dramatic thread in Episode 2 unfolds as follows. Opening the front door of his house, Peter Kingdom (Stephen Fry), a good-hearted country solicitor is confronted by two distressed village yokels, organizers of a local dyke-leaping contest. "Health and safety want to close down the tournament”, blurts out the first villager in a broad Norfolk twang ${ }^{[11]}$.

The scene immediately cuts to a dyke-leaping takeoff platform beside a reed-lined Fenland drainage channel. Kingdom and the two yokels look down at the luminous jacket and rotund proportions of a safety inspector, who is probing the mud beside the dyke. "He's worried the competitors will slip on take off and fall over", says the first yokel. "But that's what the whole sport's about", retorts the second. Kingdom muses, as if addressing the world in general, "Well ... If people could resist the urge to find someone to sue each time they sustained a small bruise, this would not be an issue, would it?"

The OHS Inspector climbs out of drain, officiously approaches the three men and hands Kingdom an official-looking form. "Sorry”, he says, “that's too dangerous. I'm serving you with a non-compliance notice”. He stumps off. Kingdom sagely regards the retreating luminous jacket and muses, "Suppose we come up with a plan B?” And they did.

The Kingdom writing team has clearly reflected some of the more common urban myths (or half-truths) at large in the community. The first is that safety officials are overbearing, self-important and meddlesome fun-killers. Second, it is perceived that the rise of litigation in all aspects of the community and work has led to excessive caution and disproportionate risk control. Third, restrictive safety rules are seen as just another aspect of an over-regulated society (the so-called Nanny State) that requires circumvention.

Two years later, on 20 April 2009, the respected BBC current affairs program Panorama went to air with "May Contain Nuts" (clearly a provocative title), an examination of OHS guidelines and regulations in Britain ${ }^{[12]}$. During the program, presenter Quentin Letts, a columnist with Britain’s Daily Mail, investigated urban myths concerning the (supposed) mindless application of health and safety regulations in Britain. Some stories were supported by fact, while others proved to be untrue - for example, "a rule banning the sale of ice cream topping for fear employees may slip on scattered hundreds and thousands”. During the program, Letts also “learned of the stark reality” associated with occupational risks in Britain's construction industry, where six workers are killed every month ${ }^{[13]}$.

In closing, Letts suggests that as we are bombarded with a plethora of safety signs, information and instructions, we may fail to distinguish dross from important warnings, guidance and rules. He concludes that, "unless we resist pointless meddling, unless we start taking more responsibility for ourselves, safety will become a joke. A truly dangerous joke” ${ }^{\text {[14] }}$. 
As “Witch Finder General” for the Daily Mail's "inquisition” into health and safety, Letts was perhaps not the best choice for the program. However, some home truths can be distilled from the Panorama investigation - notably, that overbearing regulation and control can smother personal responsibility and initiative. Interestingly, during the program Judith Hakitt, chair of Britain's Health and Safety Executive (HSE) endorsed David Tregoweth's thoughts concerning flat performance, commenting that: "While there has been consistent improvement (in OHS performance) over the past 30 years, that trend has flattened out in recent years” ${ }^{[15]}$. This theme has been echoed in Australia.

Further traction in the "knock health and safety" campaign was again provided by David Cameron (this time in election mode) when he announced: "I think we will all concede that something has gone seriously wrong with the spirit of health and safety in the last decade ... It is clear that what began as a noble intention to protect people from harm has mutated into a stultifying blanket of bureaucracy, suspicion and fear” ${ }^{[16]}$.

More recently, Stephen Fry was at it again - this time in the BBC comedy show QI. At the beginning of the show, Fry welcomed viewers to "a bracing dose of health and safety gone mad". Appropriately, panel members were dressed in yellow safety vests, hard hats and safety glasses. The humor began as Fry introduced a bellows device commonly employed in the nineteenth century to resuscitate drowning victims. It escalated as Fry explained that the bellows were used to pump tobacco smoke into a victim's anus in the belief that it would save their life. According to Fry, these devices were as commonly seen alongside European bodies of water as life rings ${ }^{[17]}$.

In Episode Nine of Pith-e Production's Web-based, comedy Safety Geeks, two Safety Geeks inspect a meatpacking factory. Passing a sliding door, a "Geek" inspector (Tom Konkle) says: "Sliding door hazard, fifteen hundred dollar fine". "What?!" exclaims the factory manager. "No push and pull signs on it”, replies the inspector. "You can’t push or pull a sliding door”, points out the exasperated manager. "We are here to see that you don't”, retorts the inspector ${ }^{[18]}$.

Back in the real world, a man drowned in a meter-deep pond while a policeman, paramedics and a fire crew stood by. Reports clamed that emergency people on the scene were instructed by superiors not to enter the pond as they had not been trained under appropriate health and safety guidelines. Commenting on this event, Stephen Glover claims that "we are the unfortunate children of a hectoring, essentially well meaning yet ham fisted Nanny, who continues, in spite of the evidence to insist she knows best” ${ }^{[19]}$.

In addressing the sometimes hysterical comment, half-truths and fictional constructions perpetrated in the electronic and print media, we can employ the notion that there is no smoke without fire, and that a half-truth is by definition half true. The trick, however, lies in discerning which half is fact and which fiction. No affair has been more convoluted, manipulated and distorted to serve individual purpose and propaganda than the notorious "conker” incident that occurred in the United Kingdom ${ }^{[20]}$.

\section{The great conker caper: a lesson somewhere}

There is nothing like banning traditional activities such as pancake races, cheese rolling or skipping to stir up community resentment in the United Kingdom. The conker affair arose in 2004 when head teacher Shaun Halfpenny organized a game of conkers, but asked participating children to wear safety goggles. Seizing an opportunity to further its crusade against "silly" health and safety rules, Britain's Daily Mail declare that: "Meddling bureaucrats and overbearing council officials and teachers are at fault with their lunatic, life-killing regulations" "21]. A local parents claimed: "It's been a good year for conkers this autumn, but I have seen a lot of them lying around uncollected. This health and safety obsession may be part of the reason". A mother commented: "We are wrapping our children up in cotton wool. The risk of damaging your eyes while playing conkers must be a million to one" ${ }^{[22]}$. 
HSE agreed with the mother, commenting that: "Realistically, the risk from playing conkers is incredibly low and just not worth bothering about. If kids deliberately hit each other over the head with conkers, that's a discipline issue, not health and safety" ${ }^{[23]}$. Interestingly, many children seemed to believe that wearing goggles to protect their eyes while playing conkers was a good idea and did not impede their enjoyment of the game!

Reflecting on the affaire, teacher Shaun Halfpenny confessed:

During the Thatcher and Major Conservative administrations the health and safety culture was brought to bear in schools. Like all head teachers, I spent tedious hours drawing up policies and writing risk assessments for all activities. It was therefore somewhat tongue in cheek that I alerted the media to the conkers-with-goggles story. I never dreamed it would eventually go global ${ }^{[24]}$.

John Holden, president of the Institution of Occupational Safety and Health (IOSH), quickly responded to Halfpenny's confession and "bit of fun" in a letter to The Guardian, grumbling: "We (IOSH) didn't know whether to laugh or cry. But on the lighter side, Mr Halfpenny's 2004 conkers 'ban' gave us a way to use the story to expose the great health and safety myth, where over-zealous interpretation of health and safety law, and plenty of encouragement from mischief making media, has fostered a risk-averse culture” ${ }^{[25]}$. Holden sheeted home the blame, explaining:

This confusion is fueled by fears of litigation (even though claims have remained flat), a growing tendency to use health and safety as an excuse not to do things, and a disturbing lack of confidence in deciding what is and isn't safe...On the darker side, the Conker story has continued to be reported as fact that wearing safety goggles was imposed by OHS rather than being a sensible choice made by individuals. This has allowed the wider health and safety myth to take root and flourish ... The great danger of trivializing our health and safety is, of course, that we fail to protect ourselves when it really is needed.

Drawing attention to the 81 percent fall in workplace deaths and a 72 percent fall in other reported injuries that have occurred in the United Kingdom over the past 35 years, IOSH chief executive Robert Strange added: "This formula of exaggeration, half truths, generalization and myth-making has created a great British joke, one about 'elf $n$ safety gone mad'. It has entered our social fabric, something to be shared and tut-tutted at over breakfast tables, in bars and worse, in workplaces" ${ }^{[26]}$.

\section{Homer Simpson takes up the challenge}

OHS and humor have been linked for many years, perhaps as a means of making a dull subject more interesting. In late November 2009, Britain's Royal Society for the Prevention of Accidents (RoSPA) engaged the cartoon character Homer Simpson to become an icon of its new accident-prevention campaign. In a twist of irony (or wry humor), the accidentprone Simpson was recruited by RoSPA to raise discussion concerning the biggest causes of injury and ill-health in the workplace: slips, trips, falls and bad posture. Simpson, a fictitious safety inspector in a nuclear power plant and a selfproclaimed personal disaster area, claims that because he is closely associated with accidents and dangerous incidents, he is well qualified to be put in charge of safety.

In a bitter twist of fate, RoSPA's Simpson initiative could loosely be associated with the Fukushima Daiichi Power Plant nuclear disaster in Japan. Some aspects of this incident appear - at least on the surface - to demonstrate a bumbling, clumsy and Simpson-like disaster response. According to the Scientific American, one study suggests that, "contrary to government claims, pools used to store spent nuclear fuel played a significant part in the release of the long-lived environmental contaminant caesium-137, which could have been prevented by prompt action” ${ }^{\text {[27] }}$. Employing humor as a foil and cut-through device to defend or promote health and safety is a risky tactic. Like dancing with the devil, it requires neat footwork and subtle management of the risks. 


\section{Growing disquiet in the OHS fraternity}

A review of recent OHS literature and commentary reveals a few parallel, if more considered, disquiet with the contemporary OHS paradigm. Referring to challenges with compliance, Johnstone comments that: "It may take considerable time for business organizations to reach the standards required for compliance; that legal rules and standards are often unclear about what constitutes OHS compliance” ${ }^{[28]}$. In a report prepared for the Australian film and television industry, Eaves states: "Employers in many industries often report that complying with OH\&S regulations by the book is an onerous imposition that costs them time and money" ${ }^{[29]}$.

In a landmark report prepared for the Secretary of State for Health in the United Kingdom, Working for a Healthier Tomorrow, Dame Carol Black draws attention to the nexus that exists in Britain between occupational health and mainstream health care, with a subsequent "inability to provide holistic support to patients of working age" ${ }^{[30]}$. Reflecting on this report and other contemporary issues, Professor Niki Ellis, CEO of the Institute of Compensation, Safety and Recovery Research in Australia, commented:

OHS is not fit for the 21st century. It is isolated, has a limited academic base and remit, uneven provision, lack of good quality data, a poor image and is perceived by many as the servant of the employer ${ }^{[31]}$.

The review Safety - a Wicked Problem, a study of CEOs' views of contemporary OHS, comments: "We have a complex, compliance based system in place, yet according to available evidence, outcomes have leveled off or even worsened" ${ }^{\text {[32] }}$. Steve Griffiths suggests possible reasons for this, commenting that: "For many organizations, improvements in safety

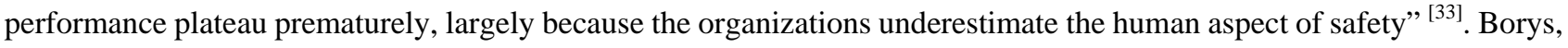
Else and Leggett agree, suggesting that, "increasingly, the limitations of an over-emphasis on documented and compliance management systems, rather than human issues have started to emerge" ${ }^{[34]}$.

Addressing the emphasis on compliance, Andrew Hopkins suggests: "There are fundamental problems with any hazard control strategy which relies on compliance with procedures" ${ }^{[35]}$. An inquiry into the Glenbrook train crash in the Blue Mountains of New South Wales, Australia, found that the railways "relied primarily on rules to assure safety". After many incidents the rulebook had become "thousands of pages, which no one fully comprehended" ${ }^{[36]}$.

Ern Millard takes up the human aspect, confessing that he has "never been a great fan of touchy feely behavioral safety concepts", but concedes that, "after the engineering phase of the hierarchy of controls has been implemented, there will be a role for this behavioral safety field". Millard emphasizes the need for a "real understanding of how humans think, the real nature of our missing or inappropriate responses so that where needed, we can move towards the safe person" ${ }^{[37]}$.

\section{Towards a safer person}

When first introduced, behavior-based safety (BBS) was viewed as a silver bullet that would slay the monster of workplace injury and mortality. It failed to live up to its promise for a number of reasons, including: expectations that behavioral change in employees would cause cultural change in organizations; focusing on symptoms rather than causes; applying off-the-shelf BBS systems without reference to organizational idiosyncrasy and context; failing to understand the root causes of human behavior and hence accident causation; generally blaming employees for safety failures; and neglecting other important OHS strategies, such as safety engineering ${ }^{[38]}$.

Robert Long believes that: The regulatory and engineering view of managing risk tends to think the best way to make people safe is to save people from themselves. This view is captured in the popular OHS Management myth of engineering out the idiot ${ }^{[39]}$. 
Clearly, safety engineering makes a valuable contribution to providing safer workplaces, but if it is overdone, it may de-skill workers in an area that should be encouraged - that is, developing the personal OHS risk management skills and knowledge that will allow them to operate safely both under and outside the protective umbrella of a regulated workplace. This issue becomes more critical as increasing numbers of workers work "precariously", as self-employed and sole practitioners, or work from home or in micro enterprises ${ }^{[40]}$.

Donald Eckenfelder suggests that BBS has certain merits, pointing out that it "focuses on the human side of safety; defines safe and unsafe behavior; involves employees in safety; requires management to put its money where its mouth is and; engenders commitment and passion, especially in the early stages” ${ }^{[41]}$. E. Scott Geller believes in people-based safety stating:

The key challenge of safety is to inspire people to be self-accountable. We need to transition from programs that promote other-directed accountability to ones that promote self-directed accountability ${ }^{[42]}$.

A report into the Glenbrook train accident emphasizes that self-accountability and risk awareness in individual workers is an imperative. It recommends a situation in which, if employees were unaware of the rules or it turned out that there were no applicable rules in a given situation, the employee would be able to work out a safe course of action for themselves ${ }^{[43]}$.

Perhaps the common thread to be found in the public and the professional conversation concerning overbearing safety rules and perceptions of a failing OHS paradigm is the notion of self-directed accountability and personal responsibility. Convoluted and complex systems, highly authoritative governance, blind obedience and top-down rather than multi-level decision-making can weaken personal initiative, resolve and accountability - dumbing down workers. Sydney Decker suggests that: "Complex systems are not safe”. They are trade-offs between multiple irreconcilable goals (e.g. safety and efficiency). Decker adds: "People have to create safety through practice at all levels in an organization" [44].

Discussing the way forward for regulators, Michael Costello, principal policy officer for WorkCover NSW, suggests that: "The challenge for work health and safety regulators is to help move all businesses away from a prescriptive mentality. This means building capability, not dependence” ${ }^{\text {[45] }}$. Capabilities are usually constructed through education, but must also be inculcated alongside a culture of personal initiative, intelligent response and individual accountability. The notion that by cultivating and nurturing the safe person, you will as a consequence build safe and sustainable communities and workplaces is worthy of deeper consideration.

Perhaps the final words should go to two Roberts - Robert Strange and Robert Long. IOSH’s Robert Strange worries that:

The public will turn its back on health and safety, encouraged to see it as more an irritation than a necessity to protect life and limb; it becomes something 'done to' them, rather than owned by them requiring their input and responsibility to make it work ${ }^{[46]}$.

Robert Long asserts that: "In a world of growing risk aversion, one could be forgiven for thinking that risk doesn't make sense. Risk elimination thinking and behavior sets a trajectory for a dumb down workplace culture ... it creates an unthinking workforce” ${ }^{[47]}$. An unthinking workforce, health and safety wise, is an accident waiting to happen - perhaps the greatest hazard of all.

\section{Stop press}

In recent months, there has been increasing mockery of OHS in Australian television programs. Commenting on a skit that appeared on ABC Television's guerilla-style comedy program A Gentleman's Guide To Knife Fighting, Actor and journalist Graeme Blundell wrote: They're making "Kitchen Sluts Five” - hammering home a "Make it Safe, be Alert, Not Inert" message ${ }^{[48]}$. During the skit, an "on-set” safety officer, who is particularly concerned about the posture of the Published by Sciedu Press 
female porn star as she negotiates a variety of "positions" in tandem with the male lead, consistently interrupted the proceedings. Clearly, he believes that future muscular-skeletal disorders will occur if appropriate ergonomics are not employed during the performance. Blundell says of the program "its dry humor deals with the way we live in a society governed by fear: fear of the authorities, fear of fellow citizens' covert suspicions and overt accusations”. As an OHS professional, if I didn’t laugh, I would have to cry.

\section{References}

[1] Many business groups in Australia bemoan the increases in OHS compliance paperwork applying the logic that the small business sector has the least capacity to cope. See Safety At Work Blog, June 8th 2012. Available from:

http://safetyatworkblog.com/2012/06/08/ohs-reform-is-a-relatively-small-regulatory-concern-for-australian-small-businesses/

[2] Braithwaite, V. Motivations, Attitudes, Perceptions, and Skills: Pathways to Safe Work. A Report prepared for Safe Work Australia, ANU, Australia. 2011; 3-4.

[3] The new Commonwealth Work Health and Safety Act 2011. The Acts and Regulations commenced on 1 January 2012.

[4] Leader of the British Conservative Party and prime-ministerial candidate David Cameron made a speech to the Policy Think Tank in London on 1 December 2009. A video of his address can be viewed at:

http://safetyatworkblog.wordpress.com/2009/12/03/tory-leader-calls-for-a-forensic-examination-of-health-and-safety-culture

[5] J. Gillard. 2008. Gillard Launches National OHS Review, Media Release. 30 July 2011. Available from: http://mediacentre.dewr.gov.au/mediacentre/gillard/releases/gillardlaunchesnationalohsreview.htm.

[6] I. Quinlan, P. Bohle. 1991. Managing Occupational Health and Safety in Australia, Macmillan, Melbourne, p. xiii.

[7] A policy statement of the American Telephone Company, quoted in WHSO course notes provided by Australian Safety Assurance Systems, delivered by the Brisbane Institute of TAFE, p. 10.

[8] D. Tregoweth. Problems with Safety Management. OHS Professional. June 2011; 7.

[9] 'Point of risk' is a phrase first coined by risk manager Adrian Savage. It brings into focus a strategy originally promoted by Robens: to provide individual workers with the skills to manage the hazards they confront by participating in their identification, evaluation and control. This is generally achieved through consultation and training.

[10] Tregoweth. Problems With Safety Management. 7.

[11] ITV Network's drama series Kingdom, Episode 2, was first broadcast in Britain on 29 April 2007.

[12] May Contain Nuts. BBC Panorama, was broadcast on BBC One on 20 April 2009.

[13] May Contain Nuts. BBC Panorama. 1 February 2012. Available from: http://news.bbc.co.uk/panorama/hi/front_page/newsid_8000000/8000495.stm

[14] Q. Letts. 2009. Britain's Zeal for Health and Safety. BBC News. 1 February 2012. Available from: http://news.bbc.co.uk/panorama/hi/front_page/newsid_7998000/7998800.stm

[15] J. Hakkit. May Contain Nuts. BBC News. 1 February 2012. Available from: http://news.bbc.co.uk/panorama/hi/front_page/newsid_8000000/8000495.stm

[16] D. Cameron. 2009. Reducing the Burden and Impact of Health and Safety. speech, 1 December. 1 February 2012. Available from: http://www.conservatives.com/News/Speeches/2009/12/David_Cameron_Reducing_the_burden_and_impact_of_health_and_saf ety.aspx

[17] QI 2011, Episode 10, ABC 1, 20 October.

[18] Safety Geek. Episode 9. 2 March 2012. Available from: http://www.funnyordie.com/videos/78fb337566/safety-geeks-svi-meatpacking-a-stripper-s-tale?rel=by_user

[19] S. Glover. Elf and Safety Regulations Gone Mad. The Week: Best Articles, US and UK. 2012; 2-8 March, p. 12.

[20] Conkers is a game played by children where a Horse Chestnut, or Conker is threaded onto a string and used to strike another Conker. It is a contest played by two opponents; the looser owns the first chestnut to be knocked off its string.

[21] Mail Online 2004, Conkersbonkers - But are We to Blame? 5 October. 10 November 2011. Available from: http://www.dailymail.co.uk/debate/columnists/article-320510/Conkerbonkers---blame.html

[22] Mail Online 2009. Pupils Ordered to Wear Goggles to Play Conkers at School in “Nanny State” Ruling. 28 October. 10 November 2011. Available from:

http://www.dailymail.co.uk/news/article-1223537/Pupils-ordered-wear-goggles-play-conkers-school-nanny-state-ruling.html\#ixz z1dG6RoBT1

[23] Health and Safety Executive. 2007. Kids Must Wear Goggles to Play Conkers. Myths of the Month. 10 November 2011. Available from: http://www.hse.gov.uk/myth/september.htm 
[24] S. Halfpenny. 2009. The Conkers with Goggles Story was a Myth. I Know, I Started It. The Guardian, 9 December. 10 November 2011. Available from: www.guardian.co.uk/commentisfree/2009/dec/09/conkers-goggles-myth-health-safety

[25] J. Holden. 2009. All Fun and Games Till Someone Loses an Eye. The Guardian. 11 December. 2 March 2012. Available from: http://www.guardian.co.uk/lifeandstyle/2009/dec/11/conker-goggles-myth-health-safety

[26] R. Strange. 2010. Elf and Safety Stories Should Carry a Warning. The Independent. 15 March. 2 March 2012. Available from: http://www.independent.co.uk/news/media/press/elf-and-safety-stories-should-carry-a-warning-1921337.html

[27] G. Brumfiel. Fukushima Nuclear Plant Released Far More Radiation than Government Said. Scientific American, 25 October. Article first published in Nature. 26 October 2011. Available from: http://www.scientificamerican.com/article.cfm?id=fukushima-nuclear-planet-released-more-radiation-government-said\&page=2

[28] R. Johnstone. From Fiction to Fact: Rethinking OHS Enforcement. paper presented at the Australian OHS Regulations for the 21st Century conference, Gold Coast, Australia. 2003; 20-22 July, p. 3.

[29] G. Eaves. Screen Production Safety Project, report prepared for Create Australia and the Australian Film and Television Industry. Create Australia. Sydney. 2004; 10.

[30] C. Black. 2008. Working for a Healthier Tomorrow, report prepared for the Secretary of State for Health, OPSI, Norwich, UK, p. 95.

[31] N. Ellis. 2010. Towards a Policy on OHS Research. paper presented to OHS Research 2010-2020 conference, Melbourne, 19-20 April.

[32] Peter Wagner and Associates. 2010. Safety, A Wicked Problem: A Review of CEOs’ Views on OHS Transformation.

[33] S. Griffiths. Achieving Cultural Change Through Safety Leadership. SIA News. 2008; 1: 5.

[34] D. Borys, D. Else, S. Leggett. The Fifth Age of Safety: The Adaptive Age. Journal of Health and Safety Research and Practice. 2009; 1(1): 19-27.

[35] A. Hopkins. Safety Culture, Mindfulness and Safe Behaviour: Converging Ideas? National Research Centre. ANU, Canberra. 2002; 12.

[36] P. McInerney. Final Report of the Special Commission of Inquiry into the Glenbrook Rail Accident, New South Wales Government, Sydney. 2001.

[37] S. Cowley. Lending Head, Heart and Hand to Safety. OHS Professional, Interview with Ern Millard. June $2012 ; 15$.

[38] S. Smith. 2007. Behavior-Based Safety: Myth or Magic. EHS Today, 1 October 1, p. 1.20 August 2011. Available from: http://ehstoday.com/mag/behaviorbased_safety_myth

[39] R. Long, J. Long. Risk Makes Sense: Human Judgement and Risk. 2nd edn, Scotoma Press, Canberra. $2012 ; 11$.

[40] M. Quinlan, C. Mayhew. Precarious Employment, Work Reorganisation and the Fracturing of OHS Management. in K. Frick, P. Jensen, M. Quinlan and T. Wilthagen (eds), Systematic Occupational Health and Safety Management. Pergamon Science, Oxford. 2000; 182.

[41] Ekenfelder quoted in S. Smith. 2007. Behavior-Based Safety: Myth or Magic. EHS Today, 1 October, p. 2. 20 August 2011. Available from: http://ehstoday.com/mag/behaviorbased_safety_myth

[42] Geller quoted in Smith, Behavior-Based Safety.

[43] McInerney. Final Report of the Special Commission of Inquiry.

[44] Decker, S. The Field Guide To Understanding Human Error. Ashgate Publishing. USA. 2006; 11.

[45] M. Costelo. Examining the Evolution of OHS Regulations. OHS Professional e-News, vol. 137. 4 September 2012. Available from: http://www.sia.org.au/browse.aspx?ContentID=examining-the-evolution-of-ohs-regulation

[46] Strange. Elf and Safety Stories Should Carry a Warning.

[47] Long and Long, Risk Makes Sense.

[48] G. Blundell. Elegant Gentlemen take sketch comedy to the sharp end. The Australian: Arts. March 30th 2013. 13 th May 2013. Available from: http://www.theaustralian.com.au/arts/review/elegant-gentlemen-take-sketch-comedy-to-the-sharp-end/story-fn9n8gph-12266079 11496 